\title{
Use of ICT in Teaching Cinema: Elements of Reflection and Practice in Higher Education
}

\author{
Ornella Castiglione ${ }^{1}$, Massimo Zucchetti ${ }^{2}$ \\ ${ }^{1}$ University of Turin, Turin, Italy \\ ${ }^{2}$ Politecnico of Turin, Turin, Italy \\ Email: ornella.castiglione@unito.it, zucchetti@polito.it \\ Received September 11 ${ }^{\text {th }}$, 2012; revised October 10 ${ }^{\text {th }}$, 2012; accepted October $22^{\text {nd }}$, 2012
}

\begin{abstract}
This paper aims to introduce utilities and dangers using ICT in teaching cinema. As digital convergence offered new opportunities in many fields, it stressed the needs to make some reflections and consequently to acquire the appropriate skills. We will discuss how cinema and ICT are related in educational contexts especially when cinema is not the specific topic. Cinema and audiovisual media are always more necessarily invited guests into lessons of various subjects and courses in order to convey messages to the students through images. As required by the dynamics of the contemporary. Then the essay introduces a practical case in which movie has contributed to develop a theme and has helped students to better understand far phenomena from them.
\end{abstract}

Keywords: Cinema; ICT; Audiovisual Media; Didactics; Images Communication

\section{Introduction}

In Italy, cinema as a specific topic is not inserted in the curriculum of any level of school and teachers of the other subjects not have the appropriate skills to deal with it, although they do watch movies in the classroom. So, in my opinion, is very important to face this topic into teachers training courses.

Only starting from this last Reform of secondary school ${ }^{1}$ will be included a specific field of study which can be chosen by students attending the final years of Liceo specializing in artistic studies. Otherwise, a few of technical institutes for graphics and advertising, which are present only in major cities (as Roberto Rossellini in Rome or Albe Steiner in Milan and in Turin, e.g.), have offered so far the opportunity to study audiovisual language in secondary school. Despite this innovation, adequate and focused training for teachers still missing. In order to supervise the preparation of teachers, last year regional offices of the Ministry of Education (2009) have established standing committees to evaluate the experience of applicant teachers which could be charged to teach cinema in these particular types of institutions.

Normally, since the first level of education, cinema at school is a support to introduce a theme (historical events, adolescence etc.), other subjects (literature, arts, history etc.) or a biography of a important character. Or in a break ... In this case, cinema is not the object of the analysis but it is a teaching tool. Then, obviously, we cannot consider this activity such as didactics of cinema but such as didactics with cinema (Marangi, 2004): this is crux of the discussion on film in education.

This brief preamble has been inserted here to explain the background scenario of higher education students when they matriculate at a humanistic or artistic faculty, where they will attend curses of cinema.

The function of cinematography in education has been

${ }^{1}$ See the guidelines at: http://www.istruzione.it/web/hub/riforma_istruzione treated by the philosopher Francesco Orestano since the beginning of last century. During a conference held in Rome, he showed some examples in order to introduce to the teachers some proposals for didactical use of the new art, aware of the impossibility to "esaurire l'inesauribile materia"2 (Orestano, 1914). Orestano has been involved in fascism and his studies was largely abandoned. But the first organic intervention has been Il Piano nazionale per la promozione didattica del linguaggio cinematografico e audiovisivo nella scuola ${ }^{3}$ because it has involved teachers and students of all levels of school in the whole nation. This wide project was devised by professor Lino Micciché and the Third University of Rome-Department of Communication and Spectacle in 1999. The main idea of the plan resides in the fact that audiovisual literacy is not only a pedagogical or social obligation but ethic (Costantino, 2005). In light of current statements of Media education, the general approach is to deal with cinema as a medium to insert as an integral resource for the training interventions in order to promote critical autonomy of the pupils (Rivoltella, 2001). Later, in the Twenty-first century, the digital convergence and the diffusion of web-based tools in learning have highlighted some problems to consider into didactics of cinema which will be faced into this essay (De Bernardinis, 2012). Finally, in order to consider use of cinema in e-learning, we could infer that there are not many achievements at the moment. Indeed, e-learning is often a didactical modality used by adults and especially teachers in in-service training and cinema is not a topic inserted at school. We can only assert the existence of some isolated experiments.

\section{Use of ICT: Utilities and Dangers}

First of all, we wish to explicit to colleagues how we define

\footnotetext{
${ }^{2}$ Exhaust the inexhaustible subject.

${ }^{3}$ The National Plan for the promotion of didactics of cinematographic and audiovisual language at school.
} 
ICT: the set of methods and technologies to receive and transmit information and contents; in this case with teaching purposes.

Due to the digital convergence, we believe that even in education a kind of revolution is being achieved. Thus, innovative and versatile digital support into didactics of cinema led to two general results:

- different didactical materials (texts, videos, pictures, etc.) can be directly uploaded in platforms and can be shared by teachers and students. In this case there are no more distinctions between video support and reader and other documents;

- devices to shoot and to make post-production are friendlyuser and low cost, so is possible to produce audiovisual documents in every school and for every single pupil.

We suggest that this two processes above mentioned could be considered in order to erase the step between enjoying and producing audiovisual arts and media. As a new didactics of cinema aims which its objectives and according to the 2.0 generation.

Indeed, introduction of web-based tools or digital supports in learning has brought many benefits, such as:

- multiply opportunities in education modalities;

- enhance creativity;

- allow a wider link with daily life;

- enrich educational offer allowing or facilitating learning especially in lifelong learning. In this case, use of e-learning matches adults updating and education needs (Garavaglia, 2010).

However, we believe that is important to consider some fixed points, such as:

- protect contents;

- have strictness in the choice and in the acceptance of the texts and in the use of the sources;

- do not replace teacher's role.

As everybody knows, web has exponentially increased the access to information and contents, thus in cinematographic fields is easier now to find movies, documentaries and audiovisual texts through various types of channels: pay tv, e-commerce sites, peer-to-peer nets, movies download portals etc. Indeed those are the channels whereby our university students build by themselves their cinematographic literacy.

As in the web everyone can be expert without a license, even cinema pupils can exercise themselves writing a review or posting a comment. We hope that during History and criticism of cinema examinations they will have acquired the adequate competencies not only through the traditional studying on the books (like all generations of students did until now) but also through practical experience. Unfortunately, excess of information and contents and the ability to publish anything without a control or without be certain of the sources made possible by Internet represents a danger for students, especially for who is not provided by the ability to discern independently. The opportunity to "write on the wall" offered by social networks, blogs, forum and other new media (Menarini, 2012) in audiovisual field has been translated in posting each type of footage, scenes and sequences on virtual places like YouTube. Sometimes they are reassembled or cut with personal graphic effects. We infer that consequences are from one side that students use like training material inappropriate sources and from the other side that they think they may say and write in a informal Register, expressing themselves without a scientific foundation as in an academic context would be required.

According to the second point above mentioned, it is easy confuse cinema, namely "the production of films as an art or industry" as defined on Oxford Dictionaries, with other types of audiovisual product (videogames, television, mobile applications, advertising etc.) enjoyed in individual contexts (homevideo, pc, mobile phones and other devices etc.). Feature of cinema is to be a mass-media production with collective projection, artistic value and social relevance. Therefore moving images or texts suitable for screen are not necessary cinema, even if the same support or the same device can be used (Figure 1).

We would like to stress this point because, since the beginning, cinema had to fight to be considered an art. Afterwards, it owned a heritage, some theories and a specific codified language (a grammar, as someone said) but in Italy, for example, only in the Seventies, with the transformation of the universities in mass-university, there were the first chairs of Film history unrelated to those of Aesthetics or other disciplines (Aristarco, 1991). Only in 1987 the course of History and criticism of cinema given in higher education has been introduced at Lincei Academy of Rome, one of the most ancient European cultural institutions (http://it.wikipedia.org/wiki/Guido_Aristarco). Despite the scientific recognition of the discipline has been established, cinema in educational context is often treated in hybridizing options (e.g. cinema and literature, cinema and visual arts). The paradox resides in diffusion of all the audiovisual media made possible by digital convergence and ICT tools and, at the same time, the involution of the cinema towards other kinds of visual representation.

\section{Why Use Cinema in Education?}

Cinema is a category of our present. Understanding movie framework is a way to exercise ourselves to understand life occurrences. Cinema is a constitutive and not optional element of our contemporary culture (De Bernardinis, 2012). But nevertheless new generations use to learn about life through the screen, they paradoxically are not able to correctly decode an image because they do not know the audiovisual language and so they do not possess the keys of interpretation of moving images. This lack of knowledge is due to the fact that school fails to provide an adequate preparation, such as film literacy.

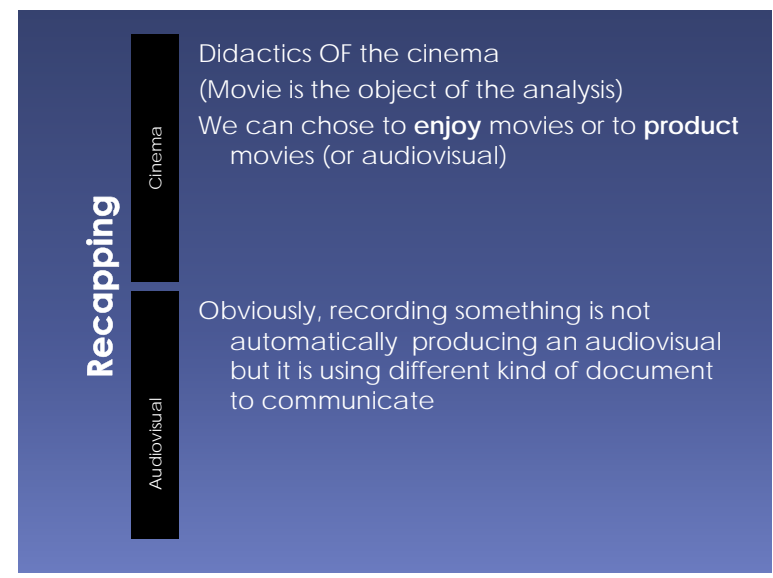

Figure 1.

Recap of main concepts regarding cinema and audiovisual media or audiovisual texts. 
Moreover, they cannot distinguish between the various forms of communication, the tools used to convey them and specific languages.

In order to set some basic principles and to recapitulate what has been said, below there will be some statements that correspond to distinct sub-paragraphs:

\section{Cinema Is a Medium}

Through a movie an author wants to communicate a message to the audience. To can efficiently communicate it, the specific audiovisual language should be known. From one side there is the shot and from the other side there is the reality. I.e. the part of exposed film (or of occupied digital support) and all what happens in front of the camera. Despite the "impression of reality" vaunted by the cinema since its inception and the alleged "transparency of image", the two dimensions cannot coincide. Camera cut out from reality a portion of space for a certain duration in time: this is the shot, the basic element of film language (Costantini, 2005).

\section{The Cinema and the World}

The cinema and the world are closely linked but to understand the language of the cinema we need to know that it is symbolic and world is real (Figure 2).

Besides they are two different complementary faces of an entire sphere. We infer that this model originates from the Baroque period in which the theater and the world were completely penetrated. They were simulacrum by each other. The cinema in its primordial form has played the reality, then indulged its natural need to tell and finally has invented own manipulative strategies to represent reality. The relation between cinema and society is dual: with the efficient synthesis of the Italian film theorist Francesco Casetti, we highlight from one side the ability of cinema to reflect the behavior of the society and from the other side its ability to intervene in social processes, becoming a "social agent".

\section{Images Communication}

The cinema is made by images ( 24 per second). Since that images are characterized by many codes (they are polysemic), a message made by images (or made by moving images) needs the keys of interpretation to be understood by people (and it also depends from time and culture). As we know, feature of images is the immediacy in the communication of the message. Indeed, since the Twenties many governments used documenttaries to educate the people, especially when they were largely illiterate and distributed in a vast territory. As asserted by Wunenburgher, cited by Marangi, no linguistic transcription of a message can never be as effective as the image. Because vision is a primary function of human beings (Marangi, 2004).

Finally, please note that interpretation of a movie can never be final.

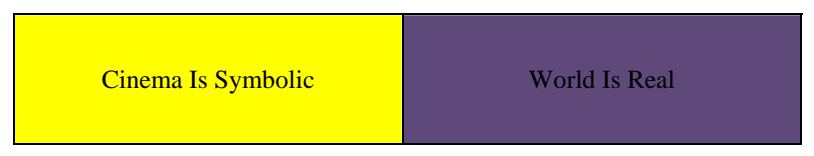

Figure 2.

Complementary colors for the cinema and the world.

\section{The Channel}

Since that we live in the digital era, we can use digital supports to communicate a content. Digital supports allow using different types of documents (text, pictures, audio, video). We can also choose different channels (cinema, TV, internet, radio, etc.) without changing our message. So we can record lessons or every kind of activities and enjoy it as video format. But to make a movie is a different project although we can have fun experimenting in the way that we think best suits our needs.

Finally, in the activity of making a movie at school we can state that classroom is a group as workers on the set of a movie, so there are many relations between the cooperative learning and making a movie.

\section{The Necessarily Invited Guests in Higher Education}

\section{Atoms and Screen: A Pattern}

A good example of the use of cinema in higher education is the following one. In the lass given at Politecnico di Torino (Italy) ${ }^{4}$, in the frame of the degree in Nuclear and Energy Engineering, called History of Nuclear Energy, an intensive use of audiovisual means has turned out to be an excellent way to involve students into the real atmosphere and meaning of the lass. Besides some classics, like The Atomic Café (Rafferty \& Loader, 1982) (Figure 3) and The day after (Meyer, 1983), a series of audiovisual documents related to the history of nuclear energy, and in particular to the making of atomic bomb and Manhattan Project, have constituted a relevant part of the lass, and turned out to be the distinctive point that made the students appreciate that lass as one of the best in the whole offer of Politecnico.

\section{Some Suggestions}

We are well aware of the difficulties in presenting suggestions to teachers working in higher education because they

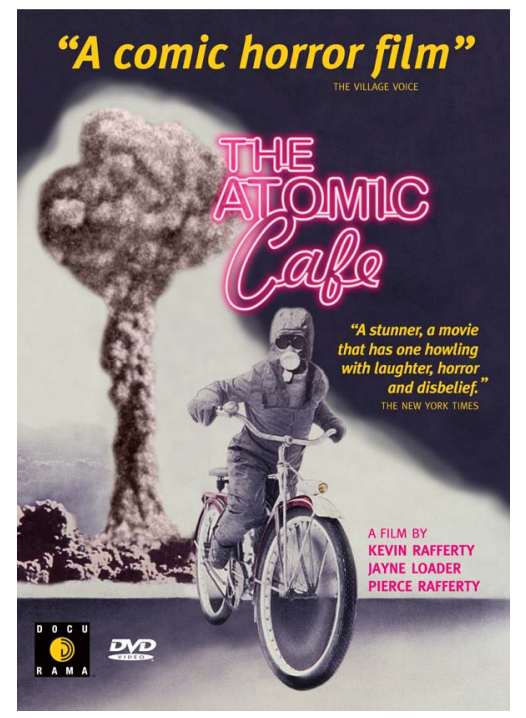

Figure 3.

Poster of the movie The Atomic Café. 
transmit knowledge that have left grow in them for a long time. What we are glad to do is leaving a little contribute to teachers who want to use movie in the classroom, sharing some reflections derived from our experience:

- Know the entire audiovisual document though has been chosen to project only one sequence;

- Know principal information about the author, the social context and the genesis of the movie;

- Present the movie before the projection, stay into the classroom during the projection and not leave pupils immediately after the projection;

- Explain clearly the purpose of the vision;

- Since that cinema is content but is also a specific language, should be clearly explained the object of the vision and the relation with the topic of the course;

- Be aware of power and feature of images communication.

\section{Conclusion}

This young generation is growing up through "like" expression and copy-and-paste system, so how can we expect to achieve our didactical aims? Through a traditional way, as we learned when we was pupils? Personally, we are passionate about our specific disciplines just through traditional classes but we believe it would be like to be silent about that twenty years have passed outside the classroom. Therefore it would be incoherent. Otherwise we could erase all our experience and indulge our students to achieve their appreciation, or their "Like", according to the "monosyllabic thought" (Menarini, 2012). We maintain that a good practice could be to continue teaching cinema starting by its history. Indeed, in our western society approach to all disciplines is diachronic. Thus, cinema may be inserted in a paradigm. The early or classic cinema represents a different vision nowadays. In my opinion, in order to passionate students, it could be more attractive than the passive acceptance of communication patterns strongly depleted. Not by chance, film critic Mereghetti highlights on the newspaper Corriere della sera a return of love for cinema that could be dissipated due to risks that reside on the web (Mereghetti, 2012).

In conclusion, we should remind that on line or blended didactics are teaching methods, digital devices are tools through which to receive or insert contents and new media are channels useful to convey a message. Though digital tools can be related with an innovative pedagogy because they present a new way to participate at school (interactivity, ability to present works, discussion of contents through forums etc.), ICT tools are didactical supports which permit to teachers to manage programs as all the other aspects of daily life.

\section{Acknowledgements}

We would like to thank the National Agency of European Lifelong Learning Program and the University of Santiago de Compostela-Faculty of Education sciences that organized and hosted the Study visit Towards flexible, innovative and creative teaching and learning using web-based tools held in June 2012 where we all put the seeds for this discussion.

\section{REFERENCES}

Aristarco, T., \& Orto, N. (1991). The didactical screen. Bari: Dedalo. Costantino, M. (2005). The National Plan for the promotion of didactics of cinematographic and audiovisual language at school. Milano: Francoangeli.

De Bernardinis, F. (2012). Chi ha paura del cinema in cattedra? Segnocinema, $175,15-37$.

Garavaglia, A. (2010). Online didactics. Form patterns to techniques. Milano: Unicopli.

Marangi, M. (2004). Insegnare cinema. Torino: Utet.

Menarini, R. (2012). New forms of film culture. Milano: Mimesis.

Mereghetti, P. (2012). Cinefili spegnete YouTube. La Lettura, Corriere della sera, 2-3.

Ministry of Education (2009). Reform of Italian educational system. URL (last checked 3 September 2012). http://www.istruzione.it/we b/hub/riforma_istruzione

Orestano, F. (1914). Motion pictures and scholastic education. In Proceedings of Minerva National Institute (pp. 5-13). Rome: Minerva National Institute.

Oxford Dictionaries. URL (last checked 7th September 2012). http://oxforddictionaries.com/definition/english/cinema?q=cinema

Rivoltella, P.C. (2001). Media education: Modelli, esperienze, profilo disciplinare. Rome: Carocci.

Wikipedia. URL (last checked 7 September 2012). http://it.wikipedia.org/wiki/Guido_Aristarco 